\title{
Obesity and pregnancy: a transversal study from a low-risk maternity
}

Ana Carolina S Calderon, Silvana M Quintana, Alessandra C Marcolin, Aderson T Berezowski, Luiz Gustavo O Brito, Geraldo Duarte and Ricardo C Cavalli

\begin{abstract}
Background: Obesity is a public health problem and is increasing in all populations, including pregnant women. It influences maternal and neonatal outcomes; however, data are scarce in developing countries. We aimed to compare perinatal results between obese and non-obese pregnant women in a low-risk maternity.

Methods: Transversal study of 1,779 40-week-pregnancies from 2005 to 2009 that completed a standard questionnaire with sociodemographic, obstetrical and neonatal variables and performed an ultrasound with amniotic fluid index (AFI) measurement and foetal vitality (FBP, non-stress test). They were analysed about their association with obesity on pregnancy.

Results: When compared with non-obese women, the group of obese patients had higher systolic (118.1 vs $109.2 \mathrm{mmHg} ; p<0.01)$ and diastolic (76.6 vs $70.4 \mathrm{mmHg} ; \mathrm{p}<0.01)$ pressure levels, AFI (12.52 vs. $9.61 \mathrm{~cm} ; \mathrm{p}=0.02)$, presence of meconium on labour (20.52 vs. 14.67\%; $p=0.02$ ), birthweight (3602 vs. $3437 \mathrm{~g} ; \mathrm{p}<0.01$ ) and caesarean section (39.74 vs. $29.98 \%, p<0.01$ ).

Conclusions: Labour induction before 40 weeks in the antenatal period associated with foetal weight estimation should be considered as a recommendation for decreasing high percentages of caesarean delivery found in obese women.
\end{abstract}

Keywords: Obesity, Pregnancy, Perinatal care, Induction of labour

\section{Background}

Obesity constitutes a major public health issue, and can be characterized as an epidemic, that does not discriminate gender, age or socioeconomic level [1]. Diagnosis is commonly performed by calculation of Body Mass Index (BMI), whose values above $30 \mathrm{~kg} / \mathrm{m}^{2}$ are present between 15 and $20 \%$ of global population [1]. However, one group catches our attention among the obese population: women of reproductive age, because it is increasingly more frequent for this population to become pregnant above the recommended weight. When we compare this group to men with the same age or women at older ages, the former has a large prevalence of obesity [1].

In the United States, the last NHANES (National Health and Nutrition Examination Survey) found that

\footnotetext{
* Correspondence: rcavalli@fmrp.usp.br

Department of Gynecology and Obstetrics, Ribeirão Preto School of Medicine, University of São Paulo (FMRP-USP), Avenida Bandeirantes, 3900 8th floor, Ribeirão Preto 14049-900 SP, Monte Alegre, Brazil
}

$26 \%$ of non-pregnant women between 20 and 39 years were overweight and 29\% were obese from 1999 to 2002 [2]. In Australia, approximately $15 \%$ of women between 25 and 34 years were obese between 2004 and 2005 [3], a lower percentage when compared to the United Kingdom, where reports of $32 \%$ of overweight and $20 \%$ of obesity were found among women from 16 to 64 years [4]. Almost $40 \%$ of married women were obese in the United Arab Emirates [5]; in Denmark, the percentage of obese women grew from 3.1 to $7.8 \%$ in a ten-year analysis [6].

Nevertheless, not only women become pregnant overweight but also gain additional weight during gestation. A study found that obesity increased from $9.9 \%$ in 1990 to $16 \%$ in 2004 among pregnant women in the North East of England [7]. An assessment performed among developing countries has ascertained that, in thirty-six of them, the proportion of overweight and obese women 
was higher than that of recommended weight among women, especially on urban population [8].

According to the Institute of Medicine (IOM) and the National Heart, Lung, and Blood Institute of the National Institutes of Health, the recommended weight gain for obese women during pregnancy is up to 6.8 kilograms; for overweight women, gain would be from 6.8 to 11.2 kilos and for non-obese women, between 11.2 to 15.9 kilos [9]. In the United States, it was shown that one in three pregnant women will fit in these prerequisites for weight gain during pregnancy, according to PRAMS (Pregnancy Risk Assessment Monitoring System) data bank [9]. In Switzerland, it was observed that $14.2 \%$ of pregnant women gained more than 20 kilos during gestation in 2004 against a percentage of $2.6 \%$ in 1986 [10].

The excessive weight gain during pregnancy and obesity before gestation is related to higher morbidity and mortality. Among possible complications, it can be cited: abortion, congenital anomalies, thromboembolism, hypertensive disorders (gestational hypertension, preeclampsia, eclampsia and HELLP syndrome), gestational diabetes, prematurity, macrosomia, foetal death, higher percentages of anaesthetic risk, failure of labour induction and as consequence, higher indexes of caesarean section, dystocic labour, postpartum infection and haemorrhage [1,6,11-14].

Prolonged pregnancy is another theme that deserves attention, since perinatal morbidity and mortality are slightly increased in gestations over 40 weeks if foetal assessment is not correctly performed [15]. Main risk factors that can be associated with prolonged pregnancy are related to low socioeconomic level of women, excessive weight gain during pregnancy and previous prolonged pregnancy [16]. Perinatal complications associated with prolonged gestations are foetal macrosomia, placental dysfunction, acute foetal distress, oligohydramnios, meconium emission and aspiration and perinatal death [15].

The present study aims to assess the perinatal results from a cohort of pregnant obese women with gestational age over 40 weeks compared to non-obese patients from a low-risk maternity in a municipality from Southeastern Brazil.

\section{Methods}

A transversal study was undertaken at Centro de Referência à Saúde da Mulher - CRSM-MATER, between 2005 and 2009, with consecutive sampling of 1,780 patients that were receiving prenatal assistance and would be forwarded to this hospital when gestation resolution arise. This research was approved by the Institutional Reviews Board from Hospital das Clínicas da FMRP-USP and CRSMMATER and followed the STROBE protocol for observational studies (Additional file 1). Informed consent was obtained from all participants from the study. We did not have any patients that declined to participate.
The inclusion criteria were: women with 40 weeks' gestation calculated from amenorrhoea period and/or first-trimester ultrasound; singleton foetus with cephalic presentation; women with no comorbidities or gestational intercurrences. Exclusion criteria were: gestational diabetes, maternal heart diseases, changes in foetal morphology found by ultrasound, other factors that could attribute risk to current gestation, hypertensive disorders.

After 40 weeks or more, patients were clinically evaluated by non-stress test and ultrasound according to the institution protocol: prenatal consultation at 40 and 41 weeks' gestation, with further reassessments every three days (41 weeks +3 days, 41 weeks +6 days, 42 weeks) for reassessment; when gestational age (GA) was 42 weeks, pregnancy resolution was scheduled by labour induction. To elaborate this research, only data from the evaluation performed at 40 weeks gestation was used.

Antenatal cardiotocography (Toitu MT-325, Tokyo, Japan) was undertaken after the patient had an adequate diet and was positioned at horizontal decubitus with a $45^{\circ}$ angle on the headboard in a separate room. Foetal heart rate (FHR) tracings were obtained for 20 minutes with no uterine contractions and if the foetus was hypoactive or needed stimulus, a vibratory or sound stimulus was performed and FHR was recorded for more three minutes.

Foetal biophysical profile (FBP) was performed using a 5-2 MHz convex probe from a Logiq 100 Pro ultrasound (General Electric, United Kingdom) with assessment after an adequate diet with the patient positioned at horizontal decubitus. Foetal observation was done in thirty minutes to register foetal breathing movements (at least one episode of $\geq 30$ seconds), gross body movements (at least three episodes body/limb movements), foetal tone (at least one episode of active extension with return to flexion), reactive FHR (at least two episodes of acceleration with foetal movements) and amniotic fluid index (AFI) (at least one pocket of fluid measuring $\geq 2 \mathrm{~cm}$ in vertical axis), as described by Magann et al. [17]. Amniotic fluid index (AFI) was assessed using the classification proposed by Phelan, where the abdomen is divided into four quadrants, with the umbilicus delineating the upper and lower halves. The deepest, unobstructed, vertical pocket of fluid is measured in each quadrant in centimeters. The four pocket measurements are then added to calculate the AFI [17].

Dependent variables were: sociodemographic (age, race, marital status, professional activity, educational level), obstetrical (number of gestations, births and abortions, tobacco and/or alcohol use, drug addiction, systolic and diastolic blood pressure, number of prenatal consultations, cardiotocography report with 40 weeks, type of delivery (vaginal or caesarean), Bishop index, 
placental maturation grade, FBP, presence of ruptured membranes) and neonatal (new born weight and gender, presence of foetal meconium). The independent variable was the presence or absence of obesity, defined as a BMI equal to or over $35 \mathrm{~kg} / \mathrm{m}^{2}$.

For statistical analysis, continuous variables were expressed by means and analysed by t-Student test. Binomial variables were analysed by chi-square and Fisher tests. A significance level of $5 \%$ was stipulated. Missing data was treated as completely at random and used treatment was listwise deletion. Data were stored into a Microsoft Excel spreadsheet and statistics were calculated in the SPSS software (SPSS Inc., Chicago, IL, USA).

\section{Results}

Mean BMI from obese and non-obese were, respectively, $38.76 \mathrm{~kg} / \mathrm{m}^{2}$ and $25.98 \mathrm{~kg} / \mathrm{m}^{2}$. Tables 1 and 2 showed the results obtained after the comparison between obese and non-obese population. We can notice that obese pregnant women presented higher systolic and diastolic blood pressure levels than non-obese patients; however, basal blood pressure levels of obese women were below the minimum required for diagnosis of arterial hypertension.

Ultrasonographic measurement of AFI reported higher means for obese women than controls (12.52 vs. $9.61 ; \mathrm{p}=0.02)$. Another variable that showed a significant difference between these two groups was birth weight, which was higher in obese women $(3602+/-470 \mathrm{~g}$ vs. $3437+$ - -414 g; $<<0.01$ ).

About types of birth, caesarean percentages were significantly higher in obese patients than controls (39.74\% vs. $29.98 \%$ ) and it was found a statistical association with macrossomic foetuses $(\mathrm{p}<0.05)$. Obese women were also more prone to induce labour than non-obese patients, as shown in Table $3(\mathrm{p}<0.01)$.

Non-obese women presented higher incidence of ruptured membranes previous to admission. However, obese patients reported with more frequency in the presence of meconium during labour.

\section{Discussion}

Our study found that obese women have a higher risk of having their birth induced, heavier babies and more susceptible to caesarean section, in agreement with the available literature. About labour induction, our data are important to discuss the influence of obesity on birthweight during prenatal counselling and, as a consequence, in obstetrical outcomes, such as the type of birth. One study found a success rate of $60 \%$ in vaginal delivery for primiparous women and $90 \%$ for multiparous women [3].

A retrospective study including 287,213 pregnancies in London, with 176,923 non-obese women and 31,273

Table 1 Obstetric and perinatal variables and their relation with obesity during pregnancy

\begin{tabular}{|c|c|c|c|c|c|c|c|c|}
\hline \multirow[t]{2}{*}{ Variables } & \multicolumn{3}{|c|}{ Obese $\left(\mathrm{BMI}>30 \mathrm{~kg} / \mathrm{m}^{2}\right)$} & \multicolumn{3}{|c|}{ Control $\left(\mathrm{BMI}<30 \mathrm{~kg} / \mathrm{m}^{2}\right)$} & \multirow[b]{2}{*}{$\mathrm{p}^{*}$} & \multirow[b]{2}{*}{ Total $(n$} \\
\hline & $\mathbf{n}$ & Mean & SD & $\mathbf{n}$ & Mean & SD & & \\
\hline Age (years) & 222 & 25.47 & 5.29 & 1,544 & 24.11 & 5.41 & $<0.01$ & 1,766 \\
\hline Age at first pregnancy (years) & 221 & 20.76 & 4.82 & 1,543 & 20.36 & 4.42 & 0.21 & 1,764 \\
\hline Previous pregnancies & 228 & 2.29 & 1.51 & 1,550 & 2.03 & 1.39 & 0.01 & 1,778 \\
\hline Previous abortions & 228 & 0.52 & 0.98 & 1,551 & 0.21 & 0.52 & $<0.01$ & 1,779 \\
\hline Previous vaginal deliveries & 228 & 0.64 & 1.20 & 1,551 & 0.68 & 1.15 & 0.71 & 1,779 \\
\hline Previous caesarean deliveries & 228 & 0.23 & 0.42 & 1,551 & 0.16 & 0.37 & 0.01 & 1,779 \\
\hline Gestational age at $1^{\text {st }}$ US (weeks) & 127 & 15.11 & 4.74 & 1,273 & 15.09 & 4.71 & 0.96 & 1,400 \\
\hline Pre-natal attendance ${ }^{* *}$ & 91 & 8.90 & 1.55 & 761 & 8.83 & 1.73 & 0.70 & 852 \\
\hline Systolic blood pressure $\left(40^{\text {th }} \text { week }\right)^{* *}$ & 93 & 118.1 & 12.6 & 773 & 109.2 & 11.5 & $<0.01$ & 866 \\
\hline Diastolic blood pressure $\left(40^{\text {th }} \text { week }\right)^{* *}$ & 93 & 76.6 & 9.9 & 773 & 70.4 & 8.6 & $<0.01$ & 866 \\
\hline Bishop index $\left(40^{\text {th }} \text { week }\right)^{* *}$ & 93 & 1.88 & 1.47 & 773 & 2.21 & 1.80 & 0.09 & 866 \\
\hline FBP ( $40^{\text {th }}$ week $)$ & 228 & 7.89 & 0.49 & 1,538 & 7.92 & 0.38 & 0.31 & 1,766 \\
\hline AFI (40 th week) & 228 & 12.52 & 4.36 & 1,539 & 9.61 & 3.57 & 0.02 & 1,767 \\
\hline Placenta $\left(40^{\text {th }} \text { week }\right)^{* *}$ & 93 & 2.13 & 0.54 & 777 & 2.19 & 0.55 & 0.32 & 870 \\
\hline Gestational age during birth (weeks) & 229 & 40.84 & 0.71 & 1,551 & 40.75 & 0.66 & 0.06 & 1,780 \\
\hline Birthweight (g) & 229 & 3,602 & 470 & 1,551 & 3,437 & 414 & $<0,01$ & 1,780 \\
\hline Apgar $1^{\text {st }}$ minute & 229 & 7,76 & 2,00 & 1,551 & 7,90 & 2,06 & 0,33 & 1,780 \\
\hline Apgar $5^{\text {th }}$ minute & 229 & 9,53 & 0,65 & 1,551 & 9,59 & 0,78 & 0,29 & 1,780 \\
\hline
\end{tabular}

FBP - Foetal biophysical profile.

$A F I$ - amniotic fluid index.

*Statistical significance when $\mathrm{p}<0.05-\mathrm{T}$ Student test.

**Sampling less than 1,000 patients. 
Table 2 Maternal and neonatal characteristics and their relation with obesity during pregnancy

\begin{tabular}{|c|c|c|c|c|c|}
\hline Variable & Obese (n) & $\%$ & Non-obese (n) & $\%$ & $p$ \\
\hline Color & & & & & 0.69 \\
\hline White & 66 & 70.97 & 533 & 68.95 & \\
\hline Mulatto & 17 & 18.28 & 132 & 17.08 & \\
\hline Black & 10 & 10.75 & 108 & 13.97 & \\
\hline Marital status & & & & & 0.42 \\
\hline Without partner & 18 & 19.35 & 186 & 24.35 & \\
\hline With partner & 75 & 80.65 & 578 & 75.65 & \\
\hline Professional activity & & & & & 0.15 \\
\hline Without & 42 & 45.16 & 290 & 37.52 & \\
\hline With & 51 & 54.84 & 483 & 62.48 & \\
\hline Scholarity (years) & & & & & 0.98 \\
\hline $0-4$ & 26 & 27.96 & 199 & 25.75 & \\
\hline 5-8 & 33 & 35.48 & 353 & 36.48 & \\
\hline$>8$ & 34 & 36.56 & 292 & 37.78 & \\
\hline Tobacco use & & & & & 0.66 \\
\hline No & 203 & 88.65 & 1,358 & 87.61 & \\
\hline Yes & 26 & 11.35 & 192 & 12.39 & \\
\hline Alcohol use & & & & & 0.78 \\
\hline No & 223 & 97.38 & 1,515 & 97.68 & \\
\hline Yes & 6 & 2.62 & 36 & 2.32 & \\
\hline Ilicit drug use & & & & & 0.52 \\
\hline No & 228 & 99.56 & 1,358 & 99.16 & \\
\hline Yes & 1 & 0.44 & 13 & 0.84 & \\
\hline Cardiotocography & & & & & 0.35 \\
\hline Active & 211 & 92.54 & 1,374 & 89.45 & \\
\hline $\begin{array}{l}\text { Hypoactive and } \\
\text { reactive }\end{array}$ & 15 & 6.58 & 146 & 9.51 & \\
\hline $\begin{array}{l}\text { Hypoactive and } \\
\text { hyporreactive }\end{array}$ & 2 & 0.88 & 16 & 1.04 & \\
\hline Type of delivery & & & & & $<0.05^{*}$ \\
\hline Vaginal & 138 & 60.26 & 1,086 & 70.02 & \\
\hline Caesarean & 91 & 39.74 & 465 & 29.98 & \\
\hline $\begin{array}{l}\text { Ruptured } \\
\text { membranes }\end{array}$ & & & & & 0.32 \\
\hline No & 193 & 84.28 & 1,265 & 81.56 & \\
\hline Yes & 36 & 15.72 & 286 & 18.44 & \\
\hline Sex of newborn & & & & & 0.78 \\
\hline Female & 116 & 50.66 & 770 & 49.68 & \\
\hline Male & 113 & 49.34 & 780 & 50.32 & \\
\hline $\begin{array}{l}\text { Presence of } \\
\text { meconium }\end{array}$ & & & & & $0.02^{*}$ \\
\hline No & 182 & 79.48 & 1,320 & 85.33 & \\
\hline Yes & 47 & 20.52 & 227 & 14.67 & \\
\hline
\end{tabular}

${ }^{*} p<0.05-$ Chi-square test.
Table 3 Labour induction with obese and non-obese women

\begin{tabular}{llrl}
\hline & Induction & Proportion & \multicolumn{1}{l}{ Cl 95\% } \\
\hline Non obese & $531 / 1427$ & $37.21 \%$ & $34.74-39.75$ \\
Obese & $100 / 211$ & $47.39 \%$ & $40.76-54.12$ \\
\hline
\end{tabular}

obese patients has demonstrated a rate of labor induction of $15.26 \%$ in the former group, and of $24.65 \%$ in the latter group (OR 1.70 [1.64-1.76] vs. 2.14 [1.85-2.47], CI 99\%). Moreover, the study reported higher birthweight indexes and elective/emergency caesarean section rates for obese women [18]. Another cohort by Arrowsmith et al. with 29,224 pregnancies showed an increase in labour induction rates proportionally related to BMI; obese women had a higher rate of labour induction (34.4\%) than non-obese patients (26.2\%). Elective and emergency caesarean rates were also higher in obese women, as well as macrosomic foetuses [19].

One hypothesis for the increase in birthweight among obese women is the altered placental secretion of adipocins such as leptin and insulin, as well as an increase on concentrations of free IGF-1. All of them are important mediators of foetal growth, causing the increase at the offer of nutrients to the foetus by: direct increase on expression and activity of transporter proteins at the placental barrier; increased offer of nutrients on maternal circulation [20]. The exacerbated fetal growth observed among obese mothers may be an explanation for the increase in caesarean and induction rates in this group.

Blood pressure was a variable already investigated in the literature. Athukorala et al. studied 1,661 pregnancies and from this sampling, 272 were obese women, showed a statistically significant increase on mean of diastolic (DBP) and systolic blood pressure (SBP) (mean difference of $7.8 \mathrm{mmHg}$ at SBP and $6.1 \mathrm{mmHg}$ at DBP), on induction rates (relative risk of 1.78 ; $95 \%$ CI 1.512.09 ) and caesarean rates ( $R R=1.63 ; 95 \%$ CI 1.34-1.99) at obese pregnants, and that the mean birthweight among obese mothers was higher than that observed among patients with a normal BMI (mean difference of $99.7 \mathrm{~g}$ with obese patients; 95\%CI 21.3-178.2, $\mathrm{p}=0.01$ ) [3]. Although an association between obesity during pregnancy and hypertension was verified, we do not believe that basal increase of pressoric levels can predispose the development of hypertensive syndromes in pregnancy.

The presence of meconium before labour and preterm rupture of membranes was associated with obesity. However, obese women did not present lower indices of $1^{\text {st }}$ minute Apgar when compared to non-obese women and this indicates that the presence of meconium would not be associated with worse foetal well being in this group. The association between these two variables 
(meconium elimination and obesity) has not been adequately studied in the literature, and their stratification with multivariate analysis to eliminate confounding bias reinforces further investigations.

Limitations of the study were found: a multivariate analysis was not performed to decrease confounding bias among variables to determine which would be associated with obesity. However, bivariate analysis could identify major potential factors related to the main outcome. Another limitation is related to missing data. Maybe some variables would have different results using other type of treatments such as data imputation; however, we believe that these results would not be so different considering the similarity of our results with other studies.

\section{Conclusion}

We believe that prenatal counselling before completing 40 weeks of pregnancy associated with an estimate of birthweight through ultrasound fetal biometry may help in the decision of inducing labour in obese women. It may influence on obstetrical outcomes, reducing caesarean rates and minimizing post procedure complications.

\section{Additional file}

Additional file 1: STROBE Statement: STrengthening the Reporting of OBservational studies in Epidemiology.

\section{Abbreviations \\ AFI: Amniotic fluid index; BMI: Body mass index; DBP: Diastolic blood pressure; FBP: Foetal biophysical profile; FHR: Foetal heart rate; IOM: Institute of Medicine; NHANES: National Health and Nutrition Examination Survey; NST: Non-stress test; PRAMS: Pregnancy Risk Assessment Monitoring System; STROBE: STrengthening the Reporting of OBservational studies in Epidemiology}

\section{Competing interests}

The authors have declares they have no competing interests.

\section{Authors' contributions}

ACSC collected all data studies and drafted the manuscript; LGOB drafted the manuscript, performed the statistical analysis; GD/SMQ/ACM/ATB/RCC conceived the study design, contributed to an analysis of the results and coordinated the research, giving important suggestions for the final manuscript. All authors read and approved the final manuscript.

\section{Acknowledgments}

We would like to acknowledge all women who have participated in this study.

Received: 24 April 2014 Accepted: 22 July 2014

Published: 28 July 2014

\section{References}

1. Siega-Riz AM, Laraia B: The implications of maternal overweight and obesity on the course of pregnancy and birth outcomes. Matern Child Health J 2006, 10:S153-S156.

2. Odgen $\mathrm{CL}$, Carroll MD, Curtin LR, McDowell MA, Tabak CH, Flegal KM: Prevalence of overweight and obesity in the United States, 1999-2004. JAMA 2006, 295:1549-1555.
3. Athukorala C, Rumbold AR, Willson KJ, Crowther CA: The risk of adverse pregnancy outcomes in women who are overweight or obese. BMC Pregnancy Child Birth 2010, 10:56.

4. Khaskan AS, Kenny LC: The effects of maternal body mass index on pregnancy outcome. Eur J Epidemiol 2009, 24:697-705.

5. Castro LC, Avina RL: Maternal obesity and pregnancy outcomes. Curr Opin Obstet Gynecol 2002, 14:601-606.

6. Andreasen KR, Andersen ML, Schantz AL: Obesity and pregnancy. Acta Obstet Gynecol Scand 2004, 83:1022-1029.

7. Heslehurst N, Ells $\sqcup$, Simpson H, Batterham A, Wilkinson J, Summerbell CD: Trends in maternal obesity incidence rates, demographic predictors, and health inequalities in 36, 821 women over a 15-year period. Br J Obstet Gynaecol 2007, 114:187-194.

8. Mendez MA, Monteiro CA, Popkin BM: Overweight exceeds underweight among women in most developing countries. Am J Clin Nutr 2005, 81:714-721.

9. Leddy MA, Power ML, Schulkin J: The impact of maternal obesity on maternal and fetal health. Rev Obstet Gynecol 2008, 1:170-178.

10. Frischknecht F, Bruhwiller H, Raio L, Luscher KP: Changes in pre-pregnancy weight and weight gain during pregnancy: retrospective comparison between 1986 and 2004. Swiss Med Wkly 2009, 139:52-55.

11. Tsoi E, Shaikh H, Robinson S, Teoh TG: Obesity in pregnancy: a major healthcare issue. Postgrad Med J 2010, 86:617-623.

12. Sirimi N, Goulis DG: Obesity in pregnancy. Hormones 2010, 9:299-306

13. Yu CKH, Teoh TG, Robinson S: Obesity in pregnancy. BJOG 2006, 113:1117-1125

14. Jarvie E, Ramsay JE: Obstetric management of obesity in pregnancy. Semin Fetal Neonatal Med 2010, 15:83-88.

15. Olesen AW, Westergaard JG, Olsen J: Perinatal and maternal complications related to postterm delivery: a national register-based study, 1978-1993. Am J Obstet Gynecol 2003, 189:222-227.

16. Eden RD, Seifert LS, Winegar A, Spellacy WN: Postdate pregnancies: a review of 46 perinatal deaths. Am J Perinatol 1987, 4:284-287.

17. Magann EF, Isler CM, Chauhan SP, Martin JN Jr: Amniotic fluid volume estimation and the biophysical profile: a confusion of criteria. Obstet Gynecol 2000, 96:640-642.

18. Sebire NJ, Jolly M, Harris JP, Wadsworth J, Joffe M, Beard RW, Regan L, Robinson S: Maternal obesity and pregnancy outcome: a study of 287,213 pregnancies in London. Int J Obes Relat Metab Disord 2001, 25:1175-1182

19. Arrowsmith S, Wray S, Quenby S: Maternal obesity and labour complications following induction of labour in prolonged pregnancy. BJOG 2011, 118:578-588.

20. Higgins L, Greenwood SL, Wareing M, Sibley CP, Mills TA: Obesity and the placenta: a consideration of nutrient exchange mechanisms in relation to aberrant fetal growth. Placenta 2011, 32:1-7.

doi:10.1186/1471-2393-14-249

Cite this article as: Calderon et al:: Obesity and pregnancy: a transversal study from a low-risk maternity. BMC Pregnancy and Childbirth 2014 14:249

\section{Submit your next manuscript to BioMed Central and take full advantage of:}

- Convenient online submission

- Thorough peer review

- No space constraints or color figure charges

- Immediate publication on acceptance

- Inclusion in PubMed, CAS, Scopus and Google Scholar

- Research which is freely available for redistribution 